\title{
Both pre- and post-synaptic alterations contribute to aberrant cholinergic transmission in superior cervical ganglia of APP ${ }^{-/ /}$mice
}

Zhao-Lin Cai $^{\mathrm{a} \Lambda}$, Jia-Jia Zhang ${ }^{\mathrm{a} \Lambda}$, Ming Chen ${ }^{\mathrm{a}}$, Jin-Zhao Wang ${ }^{\mathrm{a}}$, Peng Xiao ${ }^{\mathrm{a}}$, Li Yang ${ }^{\mathrm{b}, \mathrm{c}, \mathrm{d}, \mathrm{e}}$ *, Cheng

$$
\text { Long }^{\mathrm{a}, \mathrm{c}} \text { * }
$$

( ${ }^{\mathrm{a}}$ School of Life Sciences, ${ }^{\mathrm{b}}$ School of Psychology, ${ }^{\mathrm{c}}$ Brain Science Institute, ${ }^{\mathrm{d}}$ Guangdong Key

Laboratory of Mental Health and Cognitive Science, ${ }^{\mathrm{e}}$ Center for Studies of Psychological

Application, South China Normal University, Guangzhou 510631, P.R. China)

Running title: Altered cholinergic synaptic transmission in $\mathrm{APP}^{-/-}$mice

Key words: amyloid precursor protein, superior cervical ganglia, cholinergic synaptic transmission, high-affinity choline transporter, nicotinic acetylcholine receptor

${ }^{*}$ Correspondence and proofs:

Cheng Long

School of Life Sciences, South China Normal University, Guangzhou 510631, China

E-mail: longcheng@ scnu.edu.cn

Phone: 011-86-135-3940-2617

Fax: 011-86-20-8521-1372

Li Yang

School of Psychology, South China Normal University, Guangzhou 510631, China

Email: yangli08@scnu.edu.cn

${ }^{\Delta}$ The first two authors contributed equally to this paper. 


\section{ABSTRACT}

Though amyloid precursor protein (APP) can potentially be cleaved to generate the pathological amyloid $\beta$ peptide (A $\beta)$, APP itself plays an important role in regulating neuronal activity. APP deficiency causes functional impairment in cholinergic synaptic transmission and cognitive performance. However, the mechanisms underlying altered cholinergic synaptic transmission in APP knock-out mice $\left(\mathrm{APP}^{-/}\right)$are poorly understood. In this study, we conducted in vivo extracellular recording to investigate cholinergic compound action potentials (CAPs) of the superior cervical ganglion (SCG) in $\mathrm{APP}^{-/-}$and littermate wild-type (WT) mice. Our results demonstrate that APP not only regulates presynaptic activity, but also affects postsynaptic function at cholinergic synapses in SCG. APP deficiency reduces the number of vesicles in presynaptic terminals and attenuates the amplitude of CAPs, likely due to dysfunction of high-affinity choline transporters. Pharmacological and biochemical examination showed that postsynaptic responses mediated by $\alpha 4 \beta 2$ and $\alpha 7$ nicotinic acetylcholine receptors are reduced in the absence of APP. Our research provides evidences on how APP regulates cholinergic function and therefore may help to identify potential therapeutic targets to treat cholinergic dysfunction associated with Alzheimer's disease pathogenesis. 


\section{Introduction}

Alzheimer's disease (AD) is threatening the health of aged population worldwide. Over three decades of research, it is well accepted that AD results from the detrimental aggregation of $\beta$-amyloid peptides $(\mathrm{A} \beta)$ derived from proteolytic processing of the amyloid precursor protein (APP) (Benilova et al., 2012; Bignante et al., 2013; Tanzi and Bertram, 2005). Unfortunately, anti-A $\beta$ therapeutics in AD is much less effective or even ineffective on clinical trials so far (Callaway, 2012; Golde et al., 2011). Nevertheless, the cognitive impairment of $\mathrm{AD}$ is considered more correlated with synaptic dysfunction (Selkoe, 2002), especially cholinergic deficits (Mufson et al., 2008; Rakonczay et al., 2005). APP is a conserved type I membrane protein and highly expressed in neurons. Apart from producing A $\beta$, APP plays a critical role in the regulation of neural activity including cholinergic synaptic function (Wang et al., 2012). It has been reported that APP deficiency causes high-affinity choline transporters (CHT) dislocation and choline uptake reduction (Wang et al., 2007; Wang et al., 2009). APP deficiency leads to impaired synaptic transmission in neuromuscular junction (NMJ) (Yang et al., 2009). However, the precised mechanism underlying altered cholinergic synatic transmission in APP knock-out mice $\left(\mathrm{APP}^{-/}\right)$ remained unclear.

Acetylcholine $(\mathrm{ACh})$ is the neurotransmitter for cholinergic synapses including connections between preganglionic and postganglionic neurons of superior cervical ganglia (SCG) (Alkadhi et al., 2005). SCG is the upmost ganglia of the paravertebral sympathetic chain. Within SCG, the preganglionic input fibers ascending in the sympathetic trunk synapse with the postganglionic neurons which innervate the neck, face and intracranial structures (Savastano et al., 2010). As one largest ganglia of peripheral autonomic nervous system, SCG is frequently used for research as synaptic connections show many similarities to the central nervous system and is relatively accessible (Jackson and Tourtellotte, 2014; Klimaschewski et al., 1996). Also, SCG has been implicated in neuropathies including Horner's syndrome, stroke and epilepsy (Ladd et al., 2014).

$\mathrm{ACh}$ is synthesized and packaged to synaptic vesicles in presynaptic compartment. ACh released from presynaptic terminal binds to acetylcholine receptors (AChRs) to elicit postsynaptic responses. The majority of $\mathrm{ACh}$ is otherwise hydrolyzed by acetylcholinesterase (AChE) to choline which can be recycled by $\mathrm{CHT}$ from synaptic cleft back to presynaptic terminal for ACh resynthesis (Sarter and Parikh, 2005). Furthermore, as for postsynaptic events, nicotinic AChRs (nAChRs) mediate fast 
synaptic transmission in the form of compound action potentials (CAPs) evoked by electrical stimulation of the preganglionic nerve of the autonomic nervous system (David et al., 2010; Gingras et al., 2007). In SCG, nAChRs consists of dominant $\alpha 3 \beta 4$ hetero-pentamers and $\alpha 7$ homo-pentamers (David et al., 2010; Putz et al., 2008), while $\alpha 4 \beta 2$ nAChRs was only detected in SCG of early postnatal mice (Scholze et al., 2011).

We report here that APP deficits attenuate cholinergic synaptic transmission in SCG that involves reduction in both presynaptic CHT levels and sequential ACh containing-vesicle numbers; and postsynaptic $\alpha 4 \beta 2$ and $\alpha 7$ nAChRs mediated activities. Our in vivo experiments provide evidences in supporting the role of APP in regulating cholinergic synaptic function, and therefore help to locate the presynaptic and postsynaptic signaling pathways by which APP contributes to cholinergic synaptic transmission.

\section{Materials and Methods}

\subsection{Animals and Reagents}

The $\mathrm{APP}^{-/-}$mice, purchased from the Model Animal Research Center of Nanjing University, were generated by intercrossing the APP heterozygous males and females as described previously (Wang et al., 2007; Yang et al., 2007; Yang et al., 2009; Zheng et al., 1995). All mice were housed at room temperature with a 12:12 hour light-dark cycle and provided with food and water. Animals were used for all experiments in this study at the age of 2-month old. All animal experiments were performed in accordance with the Guidance Suggestions for the Care and Use of Laboratory Animals, published by the Ministry of Science and Technology of China. All experimental procedures were approved by the South China Normal University Animal Care and Use Committee.

Reagents were purchased from Sigma-Aldrich (St. Louis, MO, USA) unless otherwise noted. The drugs used in this study were diluted with physiological saline which was given in equivalent volume in vehicle controls.

\subsection{Electrophysiological Procedures}

Surgical procedures were adapted from the operation of SCG in rats (Savastano et al., 2010). Two-month-old mice ( $\mathrm{APP}^{-/-}$and littermate WT) were anaesthetized with sodium pentobarbital (40 mg/kg, i.p.) and fixed supinely in a stereotaxic frame. After cutting the ventral skin of the neck vertically about $2 \mathrm{~cm}$ and displacing glands and muscles laterally, the Y-shaped carotid bifurcation was identified. SCG was exposed 
after pulling carotid bifurcation slightly with a micro glass dissecting needle. A bipolar electrode (twist-insulated Ni chrome wire) was placed on the preganglionic nerve of SCG to deliver pulse stimulations and the evoked CAPs were extracellularly recorded with a monopolar electrode (Teflon-coated stainless-steel pin, $0.1 \mathrm{~mm}$ diameter) positioned at the postganglionic trunk of SCG. A clip connected to the skin nearby served as a ground (Liu et al., 2014).

Data were obtained and analyzed by PowerLab/8sp system (ML785, AD Instrument, Australia). The CAP amplitude was determined as the vertical distance between the peak and a tangent constructed between the onset and termination of the CAP. The input-output test was conducted with a series of current stimuli: $0.5,1,1.5$, 2, 3 and $4 \mathrm{~mA}$, and then adjusted at an intensity to produce about $50 \%$ of maximal CAP as the test pulse for further experiments. Paired-pulse stimulation was performed at the inter-pulse interval of $50 \mathrm{~ms}$. Sustained firing was evoked by a train of repetitive stimulation at $10 \mathrm{~Hz}$ for $30 \mathrm{~s}$ (Krishnaswamy and Cooper, 2009). Evoked synaptic responses were delivered at $0.05 \mathrm{~Hz}$ and 3 consecutive responses were averaged to estimate the CAP components of postsynaptic nAChRs.

To evaluate the function of synaptic signal molecules, antagonists and one agonist (to enhance CHT) were applied onto the exposed SCG at the speed of $10 \mu \mathrm{L} / \mathrm{min}$ with a $10 \mu \mathrm{L}$ pipette. Antagonists were as follows: hemicholinium-3 (HC3, $10 \mu \mathrm{M}$, to inhibit CHT) (Rassadi et al., 2005), mecamylamine hydrochloride (Mec, $1 \mu \mathrm{M}$, to inhibit $\alpha 3 \beta 4 \mathrm{nAChR} ; 10 \mu \mathrm{M}$, to inhibit $\alpha 3 \beta 4, \alpha 4 \beta 2$ and $\alpha 7 \mathrm{nAChR}$ ) (Papke et al., 2001 ), dihydro- $\beta$-erythroidine hydrobromide (DH $\beta \mathrm{E}, 3 \mu \mathrm{M}$, to selectively inhibit $\alpha 4 \beta 2 \mathrm{nAChR}$ ) (Zhou et al., 2013), methyllycaconitine (MLA, $0.1 \mu \mathrm{M}$, to selectively inhibit $\alpha 7 \mathrm{nAChR}$ ) (Singh et al., 2013). The CHT enhancer used in this study was coluracetam (MKC-231) (1 $\mu \mathrm{M})$ (Akaike et al., 1998). In addition, exogenous ACh (3 $\mathrm{mM}$ ) was applied to SCG at the speed of $5 \mu \mathrm{L} / \mathrm{sec}$ with a $10 \mu \mathrm{L}$ pipette to examine the postsynaptic function (Tochitsky et al., 2012). These drugs were dissolved in physiological saline.

\subsection{Western blotting}

The western blotting was performed as described previously (Yang et al., 2009) with minimal modification. For either $\mathrm{APP}^{-/-}$or WT, a total of 12 SCGs were excised from 6 mice and combined according to genotypes. Then SCGs were homogenized by mechanical disruption in lysis buffer containing $50 \mathrm{mM}$ Tris- $\mathrm{Cl}, \mathrm{pH} 7.5,150 \mathrm{mM}$ $\mathrm{NaCl}, 1 \%$ sodium dodecyl sulfate (SDS), $5 \mathrm{mM}$ EDTA and protease inhibitors (complete Min; Roche). Homogenate was then centrifuged at 14,000 rpm for $10 \mathrm{~min}$, 
and supernatant was collected. Tissue lysates were subjected to SDS-polyacrylamide gel electrophoresis (SDS-PAGE), transferred to nitrocellulose membrane, and probed with specific antibodies against the $\alpha 4$ subunit (Millipore, 1: 1000 dilution) and $\alpha 7$ subunit (Abcam, 1: 1000 dilution) of nAChR. Anti- $\beta$-actin antibody was used as loading control. Bound antibodies were detected using horseradish peroxidase-coupled secondary antibodies (Abcam, 1: 5000 dilution) and enhanced chemiluminescence. The relative optical density of immunoreactive bands was quantified using Gel-Pro Analyzer software.

\subsection{Immunohistochemistry}

The procedures for immunohistochemistry were conducted as described previously (Liu et al., 2013) with minimal modification. The SCGs were dissected immediately and washed in phosphate-buffered saline (PBS), fixed in $4 \%$ paraformaldehyde for 3 h at $4{ }^{\circ} \mathrm{C}$, and submerged in $30 \%$ sucrose overnight. The SCGs were then dehydrated in graded ethanol, embedded in paraffin and cut with a slice thickness of $4 \mu \mathrm{m}$. The paraffin sections were baked and de-waxed. Immunostaining for $\alpha 4$ and $\alpha 7$ were carried out as follows. After wash with PBS for three times, the sections were incubated in $1 \% \mathrm{H}_{2} \mathrm{O}_{2}$ for 8 min to block the endogenous peroxidase. Following rinses in PBS for $10 \mathrm{~min}$, sections were incubated with $1 \%$ bovine serum album (BSA) for $30 \mathrm{~min}$, then the sections were incubated either with rabbit anti-nAChR $\alpha 4$ (Millipore, 1: 500) or anti-nAChR $\alpha 7$ (Abcam, 1: 500) diluted in BSA for overnight at $4{ }^{\circ} \mathrm{C}$. After primary antibody incubation, sections were rinsed and incubated with horseradish peroxidase-conjugated goat anti-rabbit IgG (Abcam, 1: 1000) diluted in BSA for $2 \mathrm{~h}$ at room temperature. The sections were washed in PBS for $10 \mathrm{~min}$ and reacted with diaminobenzidine chromogen for $20 \mathrm{~min}$ in darkness. The sections were examined under optical microscope (BX51TF, Olympus, Japan). The changes of intensity of optical density (IOD) for nAChR subunits $\alpha 4$ and $\alpha 7$ were analyzed by Image Pro-Plus software.

\subsection{Ultrastructural studies}

As described in previous reports (Krishnaswamy and Cooper, 2009); (Cai et al., 2013), the SCGs were rapidly dissected from $\mathrm{APP}^{-/-}$and WT mice, placed directly into $2.5 \%$ glutaraldehyde in $0.2 \mathrm{M}$ PBS at room temperature, and fixed for $24 \mathrm{~h}$ in darkness. The tissue was then rinsed three times in $0.2 \mathrm{M}$ PBS at room temperature (15 min each), post-fixed in $1 \% \mathrm{OsO}_{4}$ for $1 \mathrm{~h}$ at $4{ }^{\circ} \mathrm{C}$, rinsed briefly with $0.2 \mathrm{M} \mathrm{PBS}$, dehydrated in graded series of acetone concentrations up to $100 \%$, placed in $100 \%$ epoxy resin for $24 \mathrm{~h}$, and embedded in EPON812 and polymerized for $8 \mathrm{~h}$ in an oven at $70{ }^{\circ} \mathrm{C}$. The 
tissue was sectioned into $60 \mathrm{~nm}$ per micrograph with LKB ultramicrotome (LKB Corporation, Switzerland), and stained with uranyl acetate followed by lead citrate, then observed and photographed using a Hitachi-7500 transmission electron microscope. Number of presynaptic vesicles and dimensions of postsynaptic density, synaptic cleft and interface curvature were measured using Image Pro-Plus software. Presynaptic vesicle density was determined as the number of synaptic vesicles per square micrometer of profile area (Wang et al., 2005). Synaptic cleft was estimated as the mean of three values including the largest, middle, and smallest ( $\mathrm{Xu}$ and $\mathrm{Zhang}$, 2006). PSD thickness was measured at the thickest part of PSD (Xu et al., 2013). PSD length was measured from the full-length PSD along postsynaptic membrane boundary (Fukunaga et al., 2015). Curvature of synaptic interface was calculated as the arc length of synaptic interface divided by the straight length between two ends of PSD (Xu et al., 2013).

\subsection{Statistical analysis}

All data were expressed as mean \pm SEM. Origin 8.0 software was employed for generating graphs. Statistical analyses were performed with Prism6 (GraphPad Software). Input-output curves and sustained firing tests were analyzed using 2-way analysis of variance (ANOVA) followed by Tukey post hoc test for multiple comparisons. All other data were analyzed using unpaired t-test if values complied with Gaussian distribution tested by D'Agostino \& Pearson omnibus normality test, or using the nonparametric Mann-Whitney test otherwise. $\mathrm{p}<0.05$ was considered as significant difference.

\section{Results}

\subsection{APP deficiency resulted in impaired CAP in SCG in vivo}

The efficiency of synaptic transmission measured by recording of CAP can be reflected by the analysis of input-output relationship (Diogenes et al., 2011; Oddo et al., 2003). Therefore, we first evaluated the relationship between the intensity of electrical stimulation and CAP amplitude in vivo in $\mathrm{APP}^{-/-}$and WT SCG. As shown in Figure 1A, at low-intensity stimuli (less than $2.0 \mathrm{~mA}$ ), CAP amplitude was identical between $\mathrm{APP}^{-/-}$and WT. However, high intensity of electrical stimulation (2.0 4.0 mA) differentiated the reduced CAP amplitude in $\mathrm{APP}^{-/-}$from that in WT (at 2.0, 3.0 and $4.0 \mathrm{~mA}, \mathrm{CAP}$ amplitude: $1.50 \pm 0.20,2.00 \pm 0.28$ and $2.59 \pm 0.46 \mathrm{mV}$ in $\mathrm{APP}^{-/-}$vs. $2.96 \pm 0.53,4.20 \pm 0.59$ and $4.93 \pm 0.74 \mathrm{mV}$ in WT, respectively, 2-way ANOVA, $\mathrm{F}(1,18)=10.75, \mathrm{p}<0.01, \mathrm{n}=10)$, implicating an impaired cholinergic 
transmission in SCG in the absence of APP.

Did the reduction in CAP amplitude result from pre- or postsynaptic changes? With regard to this concern, we performed paired-pulse experiment, a protocol commonly used to determine presynaptic function (Yang et al., 2007; Yao et al., 2013), by applying two stimulation pulses at $50 \mathrm{~ms}$ interval. As shown in Figure 1B, the paired-pulse ratio (PPR), which was determined by the ratio of second CAP amplitude over the first one, was significantly enhanced in $\mathrm{APP}^{-/-}$compared with WT $\left(\mathrm{APP}^{-/-}\right.$ $1.04 \pm 0.03$ vs. WT $0.82 \pm 0.08$, unpaired t-test with Welch's correction (two-tailed), $\mathrm{p}<0.05, \mathrm{n}=8$ ), suggesting that attenuated synaptic transmission in $\mathrm{APP}^{-/} \mathrm{SCG}$ involves, at least in part, presynaptic defects.

\subsection{Recession of sustained firing was associated with aberrant activities of CHT in $\mathrm{APP}^{-/-} \mathrm{SCG}$}

High quality of presynaptic activity permits the persistence of high-frequency synaptic transmission. Particularly, choline uptake by CHT is a rate-limiting step during cholinergic sustained firing (Krishnaswamy and Cooper, 2009; Wang et al., 2007). Although impaired CHT expression and function had been reported in the NMJ of $\mathrm{APP}^{-/-}$mice (Wang et al., 2007), if CHT deficit occurred in SCG of $\mathrm{APP}^{-/-}$mice remained unknown. We then tested if blockade of CHT activity by HC3 would normalize the CAP differences in between $\mathrm{WT}$ and $\mathrm{APP}^{-/-}$mice (Figure 2). Interestingly, $\mathrm{HC} 3$ only normalized the PPR difference in between $\mathrm{APP}^{-/}$and $\mathrm{WT}$ SCG as PPR was identical in the presence of HC3 $\left(\mathrm{APP}^{-/-} 0.93 \pm 0.04\right.$ vs. WT $0.93 \pm$ 0.07, unpaired t-test (two-tailed), $\mathrm{p}>0.05, \mathrm{n}=8$ ) (Figure 2B). However, defect on CAP amplitude remained in the presence of $\mathrm{HC} 3$ in between $\mathrm{APP}^{-/}$and WT (Figure 2A). The results indicate that presynaptic deficit in $\mathrm{APP}^{-/-} \mathrm{SCG}$ involves altered CHT activity, while the reduction on CAP amplitude may be attributed to different mechanisms.

Altered CHT activity in $\mathrm{APP}^{-/-} \mathrm{SCG}$ was further confirmed by experiments with train stimulation. Sustained firing in SCG was elicited by a train of repetitive stimulation at $10 \mathrm{~Hz}$ for $30 \mathrm{~s}$ as previously described by other groups (Krishnaswamy and Cooper, 2009; Rassadi et al., 2005). The results showed that the firing in $\mathrm{APP}^{-/}$ SCG was dramatically declined to $57.0 \pm 6.3 \%$ of initial level after $30 \mathrm{sec}$, which was significantly lower compared with WT (2-way ANOVA, $\mathrm{F}(1,14)=6.605, \mathrm{p}<0.05$, $\mathrm{n}$ $=8$ ) where the firing sustained at $81.6 \pm 7.9 \%$ of initial level (Figure $2 \mathrm{C} \& \mathrm{D}$ ). Under the presence of $\mathrm{HC} 3(10 \mu \mathrm{M})$, the firing was sharply attenuated by a similar degree in 
both genotypes $\left(\mathrm{APP}^{-/-} 45.7 \pm 8.4 \%\right.$ of initial level vs. WT $51.9 \pm 7.3 \%$ of initial level, 2-way ANOVA, $\mathrm{F}(1,14)=0.1307, \mathrm{p}>0.05, \mathrm{n}=8$ ). In addition, we applied coluracetam (MKC-231) (1 $\mu \mathrm{M})$ (Akaike et al., 1998), a choline uptake enhancer, to $\mathrm{APP}^{-/-} \mathrm{SCG}$, which in turn increased the firing activity to the level of WT (2-way ANOVA, $\mathrm{F}(1,12)=0.0940, \mathrm{p}>0.05, \mathrm{n}=7$ ) (Figure 2C \& D). Our results suggested that APP deficiency led to the firing decline of cholinergic synaptic transmission by diminishing CHT.

The disruption of CHT abolished the difference in sustained firing between $\mathrm{APP}^{-/-}$ and WT. However, the original amplitude of CAP was decreased in $\mathrm{APP}^{-/-}$compared with WT even in the presence of HC3 $\left(\mathrm{APP}^{-/-} 0.56 \pm 0.08 \mathrm{mV}\right.$ vs. WT $1.20 \pm 0.12 \mathrm{mV}$, Mann-Whitney test (two-tailed), $\mathrm{p}<0.05, \mathrm{n}=7$ ) (Figure $2 \mathrm{C} \& \mathrm{E}$ ). Again, these results suggested that there would be other signal pathways, likely postsynaptic mechanisms involved in cholinergic transmission dysfunction with APP deficits.

\subsection{Postsynaptic nAChR alterations contributed to abnormal CAP in APP $\mathbf{A P}^{-/-}$ SCG}

To examine if impaired CAP seen in $\mathrm{APP}^{-/-} \mathrm{SCG}$ involves postsynaptic alterations as well, exogenous ACh at a concentration of $3 \mathrm{mM}$ was delivered onto SCG to induce postsynaptic responses (Tochitsky et al., 2012). Indeed, the postsynaptic potential was significantly decreased in $\mathrm{APP}^{-/-}$compared with WT SCG $\left(\mathrm{APP}^{-/-} 0.605 \pm 0.110 \mathrm{mV}\right.$ vs. WT $1.29 \pm 0.203 \mathrm{mV}$, Mann-Whitney test (two-tailed), p < 0.01, n = 7) (Figure 3), suggesting postsynaptic function was also impaired possibly due to alterations on AChRs in $\mathrm{APP}^{-/-} \mathrm{SCG}$.

Nicotinic and muscarinic receptors jointly give rise to cholinergic activities (Beierlein, 2014; Sun et al., 2013). However, cholinergic synaptic transmission is mainly mediated by $\mathrm{nAChR}$ and the possibility of APP's role in regulating $\mathrm{mAChR}$ was ruled out because our preliminary experiment turned out no significant change in atropine-sensitive component between $\mathrm{APP}^{-/-}$and WT (Figure 4, Mann-Whitney test (two-tailed), $\mathrm{p}>0.05, \mathrm{n}=7$ for all 2, 5 and $10 \mu \mathrm{M}$ atropine). In SCG, dominant subtype of $\mathrm{nAChR}$ is $\alpha 3 \beta 4$ hetero-pentamer (David et al., 2010). Herein, the contribution of $\alpha 3 \beta 4 \mathrm{nAChR}$ was evaluated by using its antagonist, $1 \mu \mathrm{M} \mathrm{Mec}$. At this does Mec selectively blocks $\alpha 3 \beta 4$ nAChR (Eguchi et al., 2007). Our results showed that evoked CAP amplitude in WT declined from $3.00 \pm 0.16 \mathrm{mV}$ to $2.44 \pm 0.37 \mathrm{mV}$ $30 \mathrm{sec}$ after Mec application, while CAP amplitude in $\mathrm{APP}^{-/-}$was decreased from 2.02 $\pm 0.22 \mathrm{mV}$ to $1.49 \pm 0.26 \mathrm{mV}$ under $\mathrm{Mec}(1 \mu \mathrm{M})$ application (Figure 5A). These 
reductions reflected the component of cholinergic synaptic transmission sensitive to 1 $\mu \mathrm{M}$ Mec. However, these decrements were not significantly different between $\mathrm{APP}^{-/}$ and WT $\left(\mathrm{APP}^{-/-} 0.41 \pm 0.17 \mathrm{mV}\right.$ vs. WT $0.56 \pm 0.14 \mathrm{mV}$, Mann-Whitney test (two-tailed), $\mathrm{p}>0.05, \mathrm{n}=7$ ) (Figure 5C), suggesting similar $\alpha 3 \beta 4 \mathrm{nAChR}$ mediated responses in between $\mathrm{APP}^{-/-}$and WT SCG.

When given a higher dose of Mec $(10 \mu \mathrm{M})$ which can block nAChR subtypes including $\alpha 3 \beta 4, \alpha 4 \beta 2$ and $\alpha 7$ (Papke et al., 2001), the experiments showed that the component of evoked CAP sensitive to $10 \mu \mathrm{M}$ Mec was significantly reduced in $\mathrm{APP}^{-/-}$compared with WT $\left(\mathrm{APP}^{-/} 0.15 \pm 0.12 \mathrm{mV}\right.$ vs. WT $1.00 \pm 0.36 \mathrm{mV}$, Mann-Whitney test (two-tailed), $\mathrm{p}<0.01, \mathrm{n}=7$ ) (Figure 5B \& C). These results suggested that APP deficiency may impair postsynaptic $\alpha 4 \beta 2$ and/or $\alpha 7 \mathrm{nAChR}$ rather than $\alpha 3 \beta 4$ nAChR. CAP was not completed blocked by $10 \mu \mathrm{M}$ Mec, which suggested other subtype receptors mediated CAP in both WT and $\mathrm{APP}^{-/-}$SCG. However, these non-identified components were unaltered since the remaining CAP was identical between WT and $\mathrm{APP}^{-/-} 7$ min after drug application (Figure 5B).

Further experiments were performed with the application of $\mathrm{DH} \beta \mathrm{E}(3 \mu \mathrm{M}$, a selective antagonist for $\alpha 4 \beta 2 \mathrm{nAChR}$ ) (Zhou et al., 2013) and MLA (0.1 $\mu \mathrm{M}$, a selective antagonist for $\alpha 7 \mathrm{nAChR}$ ) (Singh et al., 2013), respectively. As speculated, both DH $\beta E$ - and MLA-sensitive components of evoked CAP were significantly decreased in $\mathrm{APP}^{-/-}$compared with WT $\left(\mathrm{DH} \beta \mathrm{E}\right.$-sensitive: $\mathrm{APP}^{-/-} 0.50 \pm 0.08 \mathrm{mV}$ vs. WT $0.99 \pm 0.20 \mathrm{mV}$, Mann-Whitney test (two-tailed), $\mathrm{p}<0.05, \mathrm{n}=7$; MLA-sensitive: $\mathrm{APP}^{-/-} 0.19 \pm 0.06 \mathrm{mV}$ vs. WT $0.44 \pm 0.12 \mathrm{mV}$, Mann-Whitney test (two-tailed), $\mathrm{p}<$ $0.05, \mathrm{n}=7$ ) (Figure 6A). These results indicated that SCG cholinergic transmission mediated by $\alpha 4 \beta 2$ and $\alpha 7 \mathrm{nAChRs}$ was impaired due to missing APP.

We next performed western blotting and immunohistochemical staining to further investigate the cellular and molecular profile of $\alpha 7$ and $\alpha 4 \beta 2 \mathrm{nAChR}$ underlying altered synaptic transmission. Our results revealed that the level of nAChR subunit $\alpha 7$ was dramatically reduced in $\mathrm{APP}^{-/-}$compared with WT in both western blotting and immunohistochemical assay (Mann-Whitney test (two-tailed), $\mathrm{p}<0.05, \mathrm{n}=5$ ), however the level of $\mathrm{nAChR}$ subunit $\alpha 4$ was identical in both genotypes (Mann-Whitney test (two-tailed), $\mathrm{p}>0.05, \mathrm{n}=5$ ) (Figure 6B \& C). Together with functional measurement, these data suggested that APP deficits impaired $\alpha 4 \beta 2$ $\mathrm{nAChR}$ activity rather than expression level.

\section{4 $\mathrm{APP}^{-/-}$SCG demonstrated abnormal ultrastructure}


Synaptic transmission relies on the structural basis of presynaptic and postsynaptic compartments (Harris and Weinberg, 2012). Potentially, APP may serve as an adhesion molecule or trophic factor in synapse formation and modification (Muller and Zheng, 2012). To reveal changes in synaptic ultrastructure of $\mathrm{APP}^{-/-} \mathrm{SCG}$, morphological experiments were conducted with transmission electron microscope (TEM). The density of synapses in sympathetic ganglia was too low to qualify the credit of synapses amount with TEM as described previously (Krishnaswamy and Cooper, 2009). However, we observed remarkable changes in presynaptic vesicle quantity, postsynaptic density (PSD), synaptic cleft and interface curvature of synapses.

As shown in Figure 7 and Table 1, a striking reduction of synaptic vesicle number occurred in presynaptic terminals of $\mathrm{APP}^{-/-} \mathrm{SCG}$. Quantitatively, the vesicle density (number of synaptic vesicles per square micrometer of profile area) in $\mathrm{APP}^{-/-} \mathrm{SCG}$ was approximately reduced by half (Mann-Whitney test (two-tailed), $\mathrm{p}<0.05, \mathrm{n}=5$ ). PSD length in $\mathrm{APP}^{-/-}$was shorter than that in WT (Mann-Whitney test (two-tailed), p $<0.05, \mathrm{n}=5$ ), though PSD thickness kept constant (Mann-Whitney test (two-tailed), $\mathrm{p}>0.05, \mathrm{n}=5)$. These ultrastructural results revealed that APP deletion indeed impaired the morphology of cholinergic synapses. On the other hand, we found decreased synaptic cleft (Mann-Whitney test (two-tailed), $\mathrm{p}<0.05, \mathrm{n}=5$ ) but increased interface curvature of synapses (Mann-Whitney test (two-tailed), $\mathrm{p}<0.05, \mathrm{n}$ $=5$ ) in $\mathrm{APP}^{-/-} \mathrm{SCG}$. Both narrower synaptic cleft and larger interface curvature of synapses were of benefit for synaptic transmission (Di and Zheng, 2013; Hu et al., 2014), which probably compensated presynaptic and postsynaptic impairments to help synapses survive under APP deficiency.

Table 1. Comparison in synaptic ultrastructure

\begin{tabular}{lll}
\hline & \multicolumn{1}{c}{ WT } & APP $^{-/-}$ \\
\hline Vesicle density $\left(\mathrm{N} / \mu \mathrm{m}^{2}\right)$ & $370.6 \pm 96.7$ & $185.5 \pm 27.7 *$ \\
Synaptic cleft $(\mathrm{nm})$ & $20.65 \pm 2.27$ & $11.62 \pm 3.47 *$ \\
PSD length $(\mathrm{nm})$ & $525.1 \pm 57.5$ & $324.0 \pm 55.2 *$ \\
PSD thickness $(\mathrm{nm})$ & $27.88 \pm 2.92$ & $20.47 \pm 4.10$ \\
Curvature of synaptic interface & $1.097 \pm 0.038$ & $1.235 \pm 0.018 *$ \\
\hline
\end{tabular}

Values are shown as mean \pm SEM. Mann-Whitney test (two-tailed), $* \mathrm{p}<0.05$ vs WT. $\mathrm{n}=5$ for both groups.

\subsection{Asymmetric eyes in $\mathrm{APP}^{-/-}$mice}


As we found in the current study, cholinergic synaptic transmission was impaired in $\mathrm{APP}^{-/-} \mathrm{SCG}$, which is related to Horner's syndrome characterized by myosis, ptosis, enophthalmos, prolapse of the nictitating membrane and conjunctival and facial congestion (Viscasillas et al., 2013). As shown in Figure 8A, $\mathrm{APP}^{-/-}$mice presented drooping of the one side eyelids randomly and visible white discoloration and inflammatory discharge around the eyelids. Then we compared the differences between bilateral eyes by detecting delta diameter of eyeballs, which was significantly increased in $\mathrm{APP}^{-/-}$mice $\left(\mathrm{APP}^{-/-} 110.47 \pm 38.14\right.$ pixels vs. WT $29.86 \pm 2.51$ pixels, $\mathrm{p}<$ $0.05, \mathrm{n}=7$ ) (Figure $8 \mathrm{~B}$ ), suggesting that the abnormal eye conditions could be due to SCG sympathetic attenuation.

\section{Discussion}

In current study, we took advantage of APP gene knock-out mice as loss of function to investigate how the APP plays a role in cholinergic synaptic transmission. However, APP gene is deleted in whole body of the mouse. Experimental research in central nervous system cannot exclude crosstalk from other affected inputs, such as glutamatergic and GABAergic neurons. In this concern, we performed experiments in SCG which receives a prominent cholinergic innervation from the preganglionic sympathetic trunk (Mao et al., 2006). The synaptic alterations as we observed in SCG are promising in cholinergic system due to APP deficits. For further study on the role of APP in collaboration between cholinergic, glutamatergic and GABAergic system, SCG will not meet our requirements for experiments and we will move on to prefrontal cortex. Nevertheless, we report here that APP deficiency results in both presynaptic and postsynaptic defects, leading to impaired SCG cholinergic synaptic transmission. In addition to presynaptic regulation of choline uptake and vesicle pool as shown here and by others (Wang et al., 2007; Wang et al., 2005; Wang et al., 2009), our research reveals that APP is critically involved in modulating postsynaptic nAChR-mediated components. This altered cholinergic synaptic transmission in SCG of APP knockout mice attenuates sympathetic innervation to face and eyes, which could contribute to abnormal eye conditions as we observed.

\subsection{Presynaptic deficits in $\mathrm{APP}^{-/-}$SCG}

Focus of presynaptic mechanisms has been given to CHT and choline uptake for effects of APP on cholinergic synaptic activity (Wang et al., 2007; Wang et al., 2009). 
It is reported that APP regulates CHT expression and function through protein-protein interaction (Wang et al., 2007) and that the interactions of presynaptic and postsynaptic APP contributed to cholinergic synaptogensis (Wang et al., 2009). The current study further demonstrated that APP play a crucial role in SCG presynaptic cholinergic function as we observed abnormal PPR which might be resulted from $\mathrm{CHT}$ defect and fewer presynaptic vesicles in $\mathrm{APP}^{-/-}$mice. Abrogation by a $\mathrm{CHT}$ inhibitor of PPR and repetitive stimulation induced CAP decline, but not the amplitude of CAP, in WT and $\mathrm{APP}^{-/-}$suggests that presynaptic deficits in the SCG of $\mathrm{APP}^{-/-}$mice might be attributed to impaired $\mathrm{CHT}$ activities which resulted in impaired choline uptake and sequential ACh synthesis as well as a pitfall of ACh-containing vesicle numbers.

\subsection{Postsynaptic defects in APP ${ }^{-/-}$SCG}

A novel finding of the current study is that we demonstrated a critical role of APP in postsynaptic $\alpha 4 \beta 2$ and $\alpha 7$ nAChRs mediated transmission. Cholinergic synaptic transmission has been shown to be mainly mediated by $\mathrm{nAChR}$ in sympathetic ganglia (David et al., 2010), we observed a significant reduction in exogenous ACh-mediated response and a reduction in both $\alpha 4 \beta 2$ and $\alpha 7 \mathrm{nAChRs}$ function. Though the expression level of $\alpha 7 \mathrm{nAChR}$ was decreased in $\mathrm{APP}^{-/-} \mathrm{SCG}$, the expression level of $\alpha 4 \beta 2 \mathrm{nAChR}$ was unchanged. These findings suggest that APP may regulate $\alpha 4 \beta 2$ and $\alpha 7 \mathrm{nAChRs}$ in different manners. The implication of our findings will drive further research on the role of APP in $\alpha 4 \beta 2$ and $\alpha 7$ nAChR-mediated components in central nervous system, since both $\alpha 4 \beta 2$ and $\alpha 7$ nAChRs modulate the neurobiological processes underlying learning and memory in brain (Kutlu and Gould, 2015).

\subsection{Synaptic morphology deficits in APP ${ }^{-/-}$SCG}

We found in the present study that presynaptic and postsynaptic membranes were more closed as synaptic cleft became narrower in $\mathrm{APP}^{-/-} \mathrm{SCG}$. Meanwhile, curvature of synaptic interface was increased in $\mathrm{APP}^{-/-} \mathrm{SCG}$. Though these ultrastructural changes are in favor of synaptic transmission (Di and Zheng, 2013; Hu et al., 2014), impaired cholinergic transmission observed indicates that these might be a compensatory effect to cheer up the reduced SCG synaptic transmission in the absence of APP. 
In conclusion, our findings demonstrate that APP is critically required in maintaining normal cholinergic transmission in the SCG via presynaptic and postsynaptic mechanisms, and provide profound perspectives to understand the role of APP in cholinergic synaptic activities.

\section{Acknowledgements}

This study was supported by grants from The National Natural Science Foundation of China $(31171018,31171355)$, the Science and Technology Division of Guangdong (2013KJCX0054), and the National Science Foundation of Guangdong Province (2014A030313418, 2014A030313440). 


\section{Legends}

Figure 1. The input-output curves and paired-pulse test. (A) Sample traces (top) show representative CAPs recorded at the stimulation intensity of $3 \mathrm{~mA}$ in WT and $\mathrm{APP}^{-/}$. The measurement for CAP amplitude was shown as $P$ in WT trace, briefly, which is the vertical distance between the peak and a tangent constructed between the onset and termination of the CAP. Compared with WT, the input-output curve was significantly reduced in $\mathrm{APP}^{-/-}(* * p<0.01, \mathrm{~F}(1,18)=10.75, \mathrm{n}=10$ for both WT and $\mathrm{APP}^{-/}, 2$-way ANOVA). The reduction reflects a defective synaptic transmission in $\mathrm{APP}^{-/-}$SCG. (B) The PPR at the inter-pulse interval of $50 \mathrm{~ms}$ was significantly increased in $\mathrm{APP}^{-/-}$compared with WT ( $\mathrm{n}=8$ for all groups), implicating changes in presynaptic activity of $\mathrm{APP}^{-/-} \mathrm{SCG}$. Data are presented as mean \pm SEM. $* *$ p $<0.01$.

\section{Figure 2. Effects of CHT on synaptic transmission and sustained firing. (A)} Under HC3 $(10 \mu \mathrm{M})$ application, CAP amplitude in $\mathrm{APP}^{-/-}$was still less than WT (Mann-Whitney test (two-tailed), $\mathrm{p}<0.05, \mathrm{n}=7$ ). (B) PPR difference was normalized with $\mathrm{HC} 3(10 \mu \mathrm{M})$ treatment. (C) Sample traces for each sustained firing group at 1, 15 and $30 \mathrm{~s}$. (D) The onset response was recorded at $1 \mathrm{~s}$ and defined as $100 \%$ for data normalization in each group. Sustained firing in $\mathrm{APP}^{-/-}$was decreased sharply, compared with WT (2-way ANOVA, p < 0.05, F $(1,14)=6.605, \mathrm{n}=8$ ). Furthermore, inhibiting CHT by $\mathrm{HC} 3(10 \mu \mathrm{M})$ depressed the activity of sustained firing to a similar level in $\mathrm{APP}^{-/-}$and WT. In addition, with MKC-231 $(1 \mu \mathrm{M})$ application, sustained firing in $\mathrm{APP}^{-/-}$was increased and comparable to WT. These results suggested that APP deficits attenuated cholinergic firing, at least in part, by disturbing CHT. (E) The difference of original value of CAP amplitude at $30 \mathrm{~s}$ still persisted between $\mathrm{APP}^{-/}$ and WT (unpaired t test (two-tailed), $\mathrm{p}<0.05, \mathrm{n}=8$ ), even under the presence of HC3 (unpaired t-test (two-tailed), $\mathrm{p}<0.05, \mathrm{n}=8$ ), demonstrating other mechanisms more than presynaptic pathways due to APP deletion. HC3: hemicholinium-3. Values are shown as mean \pm SEM. $* p<0.05$.

Figure 3. Postsynaptic response in SCG evoked by exogenous ACh $(3 \mathrm{mM})$. Sample traces (left) was displayed individually (light grey) and superimposed to average level for WT (black) and $\mathrm{APP}^{-/-}$(grey). Compared with WT, ACh-mediated response was significantly reduced in $\mathrm{APP}^{-/-}$(Mann-Whitney test (two-tailed), $\mathrm{p}<$ $0.01, \mathrm{n}=7$ ), indicating cholinergic postsynaptic function loss due to APP deficits.. 
Figure 4. Atropine-sensitive component of CAP is rare and not significantly different between APP ${ }^{-/-}$and WT. (A) On the top panel, sample traces showed CAPs recorded before and after $5 \mu \mathrm{M}$ atropine (a competitive antagonist of the mAChR) application in WT and $\mathrm{APP}^{-/-}$, respectively. On the bottom, CAP amplitude was plotted to the concentration of atropine $(2,5$ and $10 \mu \mathrm{M})$, whereas 0 meant only vehicle (saline) treatment. (B) The histogram represented the total CAPs, as the initial level, and the components sensitive to atropine $(2,5$ and $10 \mu \mathrm{M}) . \mathrm{n}=7$ for all groups.

Figure 5. Nicotinic AChR-mediated components of evoked CAP in SCG. (A) The components sensitive to low dose $(1 \mu \mathrm{M}) \mathrm{Mec}$, which could completely inhibit nAChR subtype $\alpha 3 \beta 4$, were similar between $\mathrm{APP}^{-/-}$and WT (Mann-Whitney test (two-tailed), $\mathrm{p}>0.05, \mathrm{n}=7$ ). (B) The component was significantly reduced in $\mathrm{APP}^{-/}$ compared with WT (Mann-Whitney test (two-tailed), $\mathrm{p}<0.01, \mathrm{n}=7$ ), under the application of high dose $(10 \mu \mathrm{M}) \mathrm{Mec}$, which was strong enough to inhibit nAChR $\alpha 4 \beta 2$ and $\alpha 7$ subtypes. (C) The histogram showed intact CAPs and components sensitive to low and high doses of Mec between $\mathrm{APP}^{-/}$and WT. These results suggested that the APP deletion caused postsynaptic functional loss, likely due to nAChR $\alpha 4 \beta 2$ and/or $\alpha 7$ impairment rather than $\alpha 3 \beta 4$ alteration. Mec: mecamylamine.

Figure 6. Function and expression of $\mathrm{nAChR} \alpha 4 \beta 2$ and $\alpha 7$. (A) The components of CAP sensitive to DH $\beta E$ ( $3 \mu \mathrm{M}$, selectively inhibit nAChR $\alpha 4 \beta 2)$ and MLA $(0.1 \mu \mathrm{M}$, selectively inhibit nAChR $\alpha 7$ ) were decreased in $\mathrm{APP}^{-/-}$compared with WT (for both DH $\beta E$ and MLA treatment, Mann-Whitney test (two-tailed), $\mathrm{p}<0.05, \mathrm{n}=7$ ), indicating $\alpha 4 \beta 2$ and $\alpha 7 \mathrm{nAChR}$ function loss due to APP deletion. Sample traces (top) showed intact CAPs and the components sensitive to DH $\beta E$ or/and MLA by subtracting intact CAPs' counterparts under the presence of DH $\beta E$ or/and MLA, respectively. DH $\beta E$ : dihydro- $\beta$-erythroidine, MLA: methyllycaconitine. (B) The results showed an obvious reduction of $\mathrm{nAChR}$ subunit $\alpha 7$ level in $\mathrm{APP}^{-/-}$compared with WT, while the subunit $\alpha 4$ level is similar between both genotypes. Statistical histogram (right) was derived from images at the left. (C) Brown shows $\alpha 7$ - or $\alpha 4$-positive soma of neurons; Blue shows nuclei stained by hematoxylin. The percentage of $\alpha 7$ - or $\alpha 4$-positive neurons is determined by the number of brown cells divided by blue nuclei amount. The results revealed an unchanged $\alpha 4$ level (Mann-Whitney test (two-tailed), $\mathrm{p}>0.05, \mathrm{n}=5$ ) and a significant decline of $\alpha 7$ level compared with WT (Mann-Whitney test (two-tailed), $\mathrm{p}<0.01, \mathrm{n}=5$ ). Scare bars: $20 \mu \mathrm{m}$. Statistical histogram (right) was derived from 5 
images of immunoassaying.

Figure 7. Synaptic ultrastructure in WT and APP ${ }^{-/-}$SCG. Image samples of transmission electronic microscope (TEM) were shown for WT (top) and $\mathrm{APP}^{-/-}$ (bottom) at the magnification of 70,000. Scale bars: $200 \mathrm{~nm}$.

Figure 8. Abnormal bilateral eyes in $\mathrm{APP}^{-/-}$mice. (A) $\mathrm{APP}^{-/-}$mice exhibited observable differences between bilateral eyes sensitivity as evidenced by wincing and closure of the eyelid. Visible white discoloration and inflammatory discharge around the eyelid of the right or left eye were also observed. (B) Delta diameter between bilateral eyes was significantly increased in $\mathrm{APP}^{-/-}$compared with WT $(\mathrm{n}=7$ for all groups), implicating damage in $\mathrm{APP}^{-/-} \mathrm{SCG}$.

\section{References}

Akaike, A., Maeda, T., Kaneko, S., Tamura, Y., 1998. Protective effect of MKC-231, a novel high affinity choline uptake enhancer, on glutamate cytotoxicity in cultured cortical neurons. Jpn J Pharmacol 76, 219-222.

Alkadhi, K. A., Alzoubi, K. H., Aleisa, A. M., 2005. Plasticity of synaptic transmission in autonomic ganglia. Prog Neurobiol 75, 83-108.

Beierlein, M., 2014. Synaptic mechanisms underlying cholinergic control of thalamic reticular nucleus neurons. J Physiol 592, 4137-4145.

Benilova, I., Karran, E., De Strooper, B., 2012. The toxic A $\beta$ oligomer and Alzheimer's disease: an emperor in need of clothes. Nat Neurosci 15, 349-357.

Bignante, E. A., Heredia, F., Morfini, G., Lorenzo, A., 2013. Amyloid $\beta$ precursor protein as a molecular target for amyloid $\beta$--induced neuronal degeneration in Alzheimer's disease. Neurobiol Aging 34, 2525-2537.

Cai, Z. L., Wang, C. Y., Gu, X. Y., Wang, N. J., Wang, J. J., Liu, W. X., Xiao, P., Li, C. H., 2013. Tenuigenin ameliorates learning and memory impairments induced by ovariectomy. Physiol Behav $118,112-117$.

Callaway, E., 2012. Alzheimer's drugs take a new tack. Nature 489, 13-14.

David, R., Ciuraszkiewicz, A., Simeone, X., Orr-Urtreger, A., Papke, R. L., McIntosh, J. M., Huck, S., Scholze, P., 2010. Biochemical and functional properties of distinct nicotinic acetylcholine receptors in the superior cervical ganglion of mice with targeted deletions of nAChR subunit genes. Eur J Neurosci 31, 978-993.

Di, G., Zheng, Y., 2013. Effects of high-speed railway noise on the synaptic ultrastructure and phosphorylated-CaMKII expression in the central nervous system of SD rats. Environ Toxicol Pharmacol 35, 93-99.

Diogenes, M. J., Costenla, A. R., Lopes, L. V., Jeronimo-Santos, A., Sousa, V. C., Fontinha, B. M., Ribeiro, J. A., Sebastiao, A. M., 2011. Enhancement of LTP in aged rats is dependent on endogenous BDNF. Neuropsychopharmacology 36, 1823-1836.

Eguchi, S., Miyashita, S., Kitamura, Y., Kawasaki, H., 2007. Alpha3beta4-nicotinic receptors mediate 
adrenergic nerve- and peptidergic (CGRP) nerve-dependent vasodilation induced by nicotine in rat mesenteric arteries. Br J Pharmacol 151, 1216-1223.

Fukunaga, Y., Nakajima, E., Hatano, E., Itoh, S., Kashino, Y., Miyazawa, A., 2015. Activation of NMDA receptors thickens the postsynaptic density via proteolysis. Neurosci Res 101, 6-14.

Gingras, J., Rassadi, S., Cooper, E., Ferns, M., 2007. Synaptic transmission is impaired at neuronal autonomic synapses in agrin-null mice. Dev Neurobiol 67, 521-534.

Golde, T. E., Schneider, L. S., Koo, E. H., 2011. Anti-A $\beta$ therapeutics in Alzheimer's disease: the need for a paradigm shift. Neuron 69, 203-213.

Harris, K. M., Weinberg, R. J., 2012. Ultrastructure of synapses in the mammalian brain. Cold Spring Harb Perspect Biol 4, a005587.

Hu, S. S., Mei, L., Chen, J. Y., Huang, Z. W., Wu, H., 2014. Effects of salicylate on the inflammatory genes expression and synaptic ultrastructure in the cochlear nucleus of rats. Inflammation 37, 365-373.

Jackson, M., Tourtellotte, W., 2014. Neuron Culture from Mouse Superior Cervical Ganglion. Bio Protoc 4.

Klimaschewski, L., Kummer, W., Heym, C., 1996. Localization, regulation and functions of neurotransmitters and neuromodulators in cervical sympathetic ganglia. Microsc Res Tech 35, 44-68.

Krishnaswamy, A., Cooper, E., 2009. An activity-dependent retrograde signal induces the expression of the high-affinity choline transporter in cholinergic neurons. Neuron 61, 272-286.

Kutlu, M. G., Gould, T. J., 2015. Nicotinic receptors, memory, and hippocampus. Curr Top Behav Neurosci 23, 137-163.

Ladd, F. V., Ladd, A. A., da Silva, A. A., Coppi, A. A., 2014. Stereological and allometric studies on neurons and axo-dendritic synapses in superior cervical ganglia. Int Rev Cell Mol Biol 311, $123-155$

Liu, J., Li, G., Peng, H., Tu, G., Kong, F., Liu, S., Gao, Y., Xu, H., Qiu, S., Fan, B., Zhu, Q., Yu, S., Zheng, C., Wu, B., Peng, L., Song, M., Wu, Q., Liang, S., 2013. Sensory-sympathetic coupling in superior cervical ganglia after myocardial ischemic injury facilitates sympathoexcitatory action via P2X7 receptor. Purinergic Signal 9, 463-479.

Liu, Q.-Y., Wang, C.-Y., Cai, Z.-L., Xu, S.-T., Liu, W.-X., Xiao, P., Li, C.-H., 2014. Effects of intrahippocampal $\mathrm{GABAB}$ receptor antagonist treatment on the behavioral long-term potentiation and Y-maze learning performance. Neurobiology of Learning and Memory 114, 26-31.

Mao, D., Yasuda, R. P., Fan, H., Wolfe, B. B., Kellar, K. J., 2006. Heterogeneity of nicotinic cholinergic receptors in rat superior cervical and nodose Ganglia. Mol Pharmacol 70, 1693-1699.

Mufson, E. J., Counts, S. E., Perez, S. E., Ginsberg, S. D., 2008. Cholinergic system during the progression of Alzheimer's disease: therapeutic implications. Expert Rev Neurother 8, 1703-1718.

Muller, U. C., Zheng, H., 2012. Physiological functions of APP family proteins. Cold Spring Harb Perspect Med 2, a006288.

Oddo, S., Caccamo, A., Shepherd, J. D., Murphy, M. P., Golde, T. E., Kayed, R., Metherate, R., Mattson, M. P., Akbari, Y., LaFerla, F. M., 2003. Triple-transgenic model of Alzheimer's disease with plaques and tangles: intracellular $A \beta$ and synaptic dysfunction. Neuron 39, 409-421.

Papke, R. L., Sanberg, P. R., Shytle, R. D., 2001. Analysis of mecamylamine stereoisomers on human nicotinic receptor subtypes. J Pharmacol Exp Ther 297, 646-656.

Putz, G., Kristufek, D., Orr-Urtreger, A., Changeux, J. P., Huck, S., Scholze, P., 2008. Nicotinic 
acetylcholine receptor-subunit mRNAs in the mouse superior cervical ganglion are regulated by development but not by deletion of distinct subunit genes. J Neurosci Res 86, 972-981.

Rakonczay, Z., Horvath, Z., Juhasz, A., Kalman, J., 2005. Peripheral cholinergic disturbances in Alzheimer's disease. Chem Biol Interact 157-158, 233-238.

Rassadi, S., Krishnaswamy, A., Pie, B., McConnell, R., Jacob, M. H., Cooper, E., 2005. A null mutation for the $\alpha 3$ nicotinic acetylcholine $(\mathrm{ACh})$ receptor gene abolishes fast synaptic activity in sympathetic ganglia and reveals that ACh output from developing preganglionic terminals is regulated in an activity-dependent retrograde manner. J Neurosci 25, 8555-8566.

Sarter, M., Parikh, V., 2005. Choline transporters, cholinergic transmission and cognition. Nat Rev Neurosci 6, 48-56.

Savastano, L. E., Castro, A. E., Fitt, M. R., Rath, M. F., Romeo, H. E., Munoz, E. M., 2010. A standardized surgical technique for rat superior cervical ganglionectomy. J Neurosci Methods 192, 22-33.

Scholze, P., Ciuraszkiewicz, A., Groessl, F., Orr-Urtreger, A., McIntosh, J. M., Huck, S., 2011. Alpha4beta2 nicotinic acetylcholine receptors in the early postnatal mouse superior cervical ganglion. Dev Neurobiol 71, 390-399.

Selkoe, D. J., 2002. Alzheimer's disease is a synaptic failure. Science 298, 789-791.

Singh, N. S., Paul, R. K., Ramamoorthy, A., Torjman, M. C., Moaddel, R., Bernier, M., Wainer, I. W., 2013. Nicotinic acetylcholine receptor antagonists alter the function and expression of serine racemase in PC-12 and 1321N1 cells. Cell Signal 25, 2634-2645.

Sun, Y. G., Pita-Almenar, J. D., Wu, C. S., Renger, J. J., Uebele, V. N., Lu, H. C., Beierlein, M., 2013. Biphasic cholinergic synaptic transmission controls action potential activity in thalamic reticular nucleus neurons. J Neurosci 33, 2408-2459.

Tanzi, R. E., Bertram, L., 2005. Twenty years of the Alzheimer's disease amyloid hypothesis: a genetic perspective. Cell 120, 545-555.

Tochitsky, I., Banghart, M. R., Mourot, A., Yao, J. Z., Gaub, B., Kramer, R. H., Trauner, D., 2012. Optochemical control of genetically engineered neuronal nicotinic acetylcholine receptors. Nat Chem 4, 105-111.

Viscasillas, J., Sanchis-Mora, S., Hoy, C., Alibhai, H., 2013. Transient Horner's syndrome after paravertebral brachial plexus blockade in a dog. Vet Anaesth Analg 40, 104-106.

Wang, B., Yang, L., Wang, Z., Zheng, H., 2007. Amyolid precursor protein mediates presynaptic localization and activity of the high-affinity choline transporter. Proc Natl Acad Sci U S A 104, 14140-14145.

Wang, P., Yang, G., Mosier, D. R., Chang, P., Zaidi, T., Gong, Y. D., Zhao, N. M., Dominguez, B., Lee, K. F., Gan, W. B., Zheng, H., 2005. Defective neuromuscular synapses in mice lacking amyloid precursor protein (APP) and APP-Like protein 2. J Neurosci 25, 1219-1225.

Wang, Z., Wang, B., Yang, L., Guo, Q., Aithmitti, N., Songyang, Z., Zheng, H., 2009. Presynaptic and postsynaptic interaction of the amyloid precursor protein promotes peripheral and central synaptogenesis. J Neurosci 29, 10788-10801.

Wang, Z., Yang, L., Zheng, H., 2012. Role of APP and A $\beta$ in synaptic physiology. Curr Alzheimer Res 9, 217-226.

Xu, X., Liu, X., Zhang, Q., Zhang, G., Lu, Y., Ruan, Q., Dong, F., Yang, Y., 2013. Sex-specific effects of bisphenol-A on memory and synaptic structural modification in hippocampus of adult mice. Horm Behav 63, 766-775. 
Xu, X., Zhang, Z., 2006. Effects of estradiol benzoate on learning-memory behavior and synaptic structure in ovariectomized mice. Life Sci 79, 1553-1560.

Yang, L., Wang, B., Long, C., Wu, G., Zheng, H., 2007. Increased asynchronous release and aberrant calcium channel activation in amyloid precursor protein deficient neuromuscular synapses. Neuroscience 149, 768-778.

Yang, L., Wang, Z., Wang, B., Justice, N. J., Zheng, H., 2009. Amyloid precursor protein regulates $\mathrm{Ca}_{v} 1.2$ L-type calcium channel levels and function to influence GABAergic short-term plasticity. $\mathrm{J}$ Neurosci 29, 15660-15668.

Yao, L. H., Huang, J. N., Li, C. H., Li, H. H., Yan, W. W., Cai, Z. L., Liu, W. X., Xiao, P., 2013. Cordycepin Suppresses Excitatory Synaptic Transmission in Rat Hippocampal Slices Via a Presynaptic Mechanism. CNS Neurosci Ther 19, 216-221.

Zheng, H., Jiang, M., Trumbauer, M. E., Sirinathsinghji, D. J., Hopkins, R., Smith, D. W., Heavens, R. P., Dawson, G. R., Boyce, S., Conner, M. W., Stevens, K. A., Slunt, H. H., Sisoda, S. S., Chen, H. Y., Van der Ploeg, L. H., 1995. beta-Amyloid precursor protein-deficient mice show reactive gliosis and decreased locomotor activity. Cell 81, 525-531.

Zhou, X. J., Chen, Y. H., Ge, D. Y., Yuan, W. J., Wang, J. J., 2013. Nicotine enhances both excitatory and inhibitory synaptic inputs to inspiratory-activated airway vagal preganglionic neurons. Experimental Physiology 98, 67-80. 
A
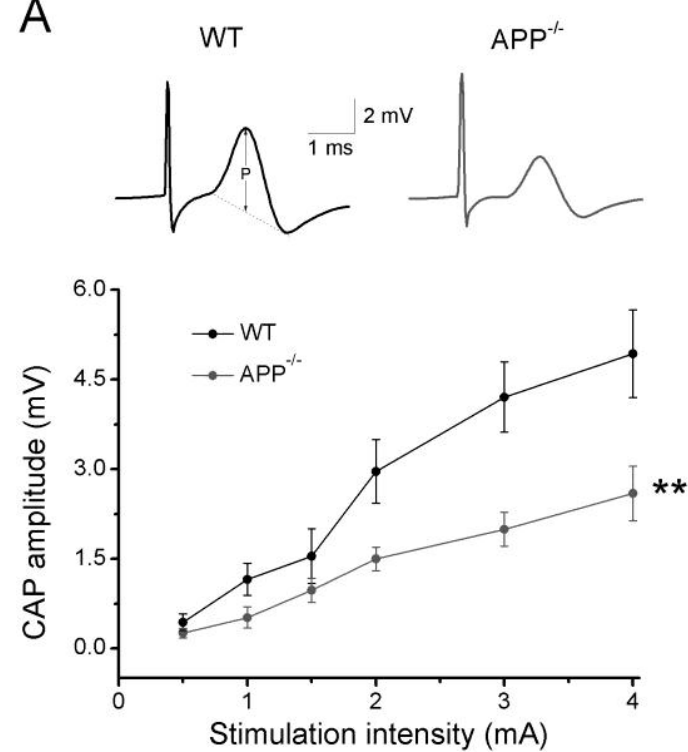

B
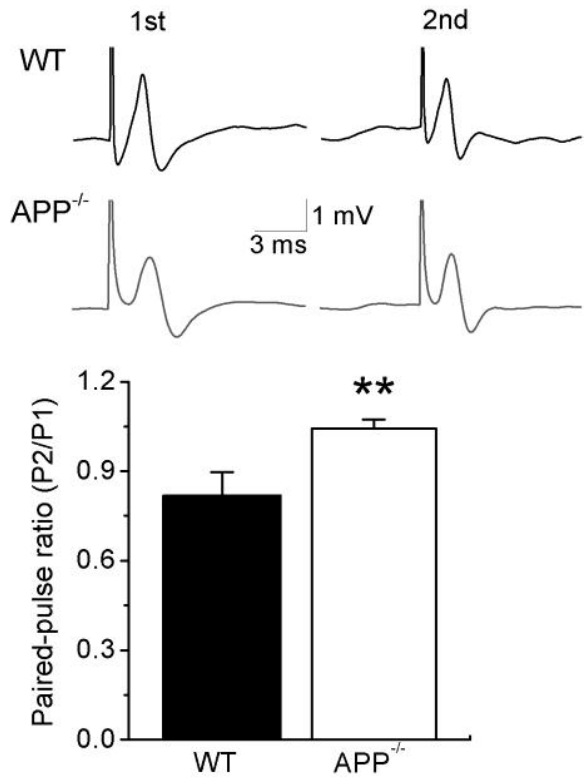


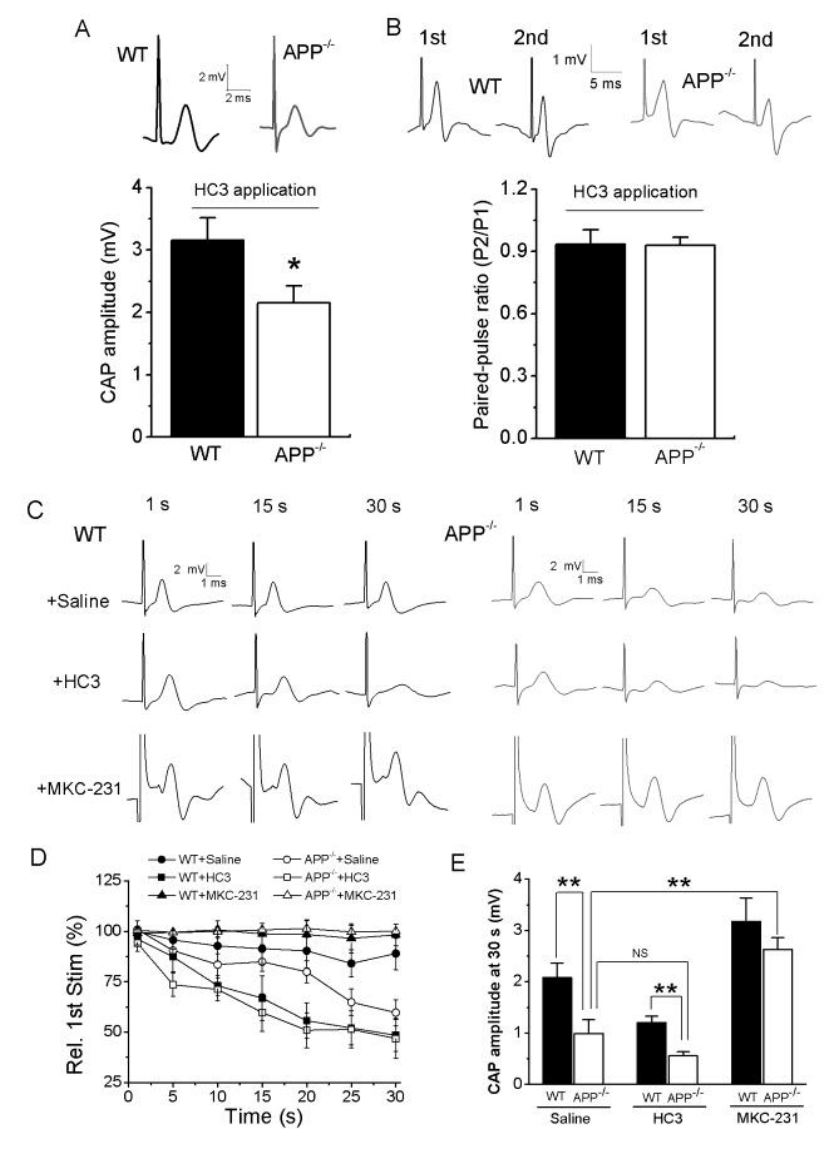




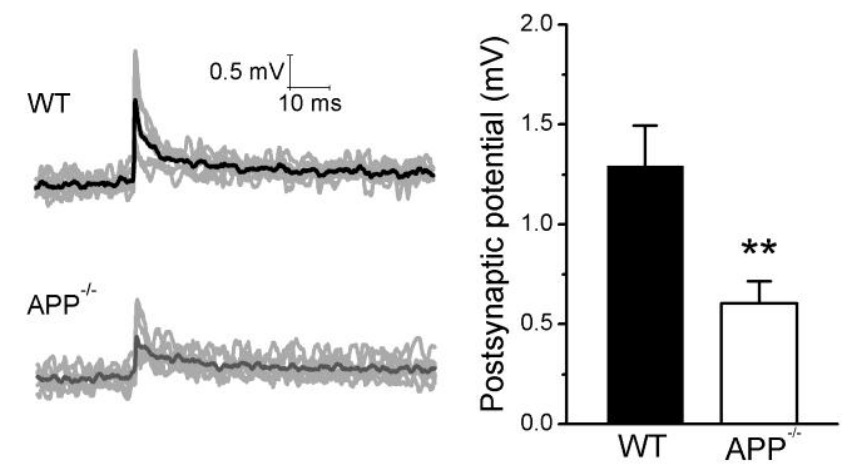




$$
1=
$$




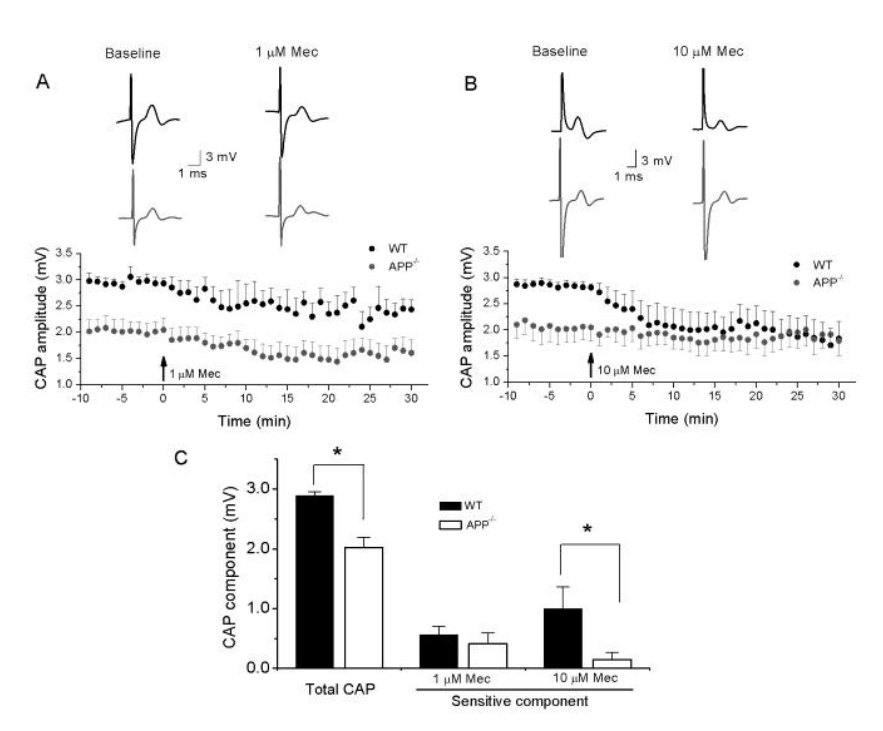




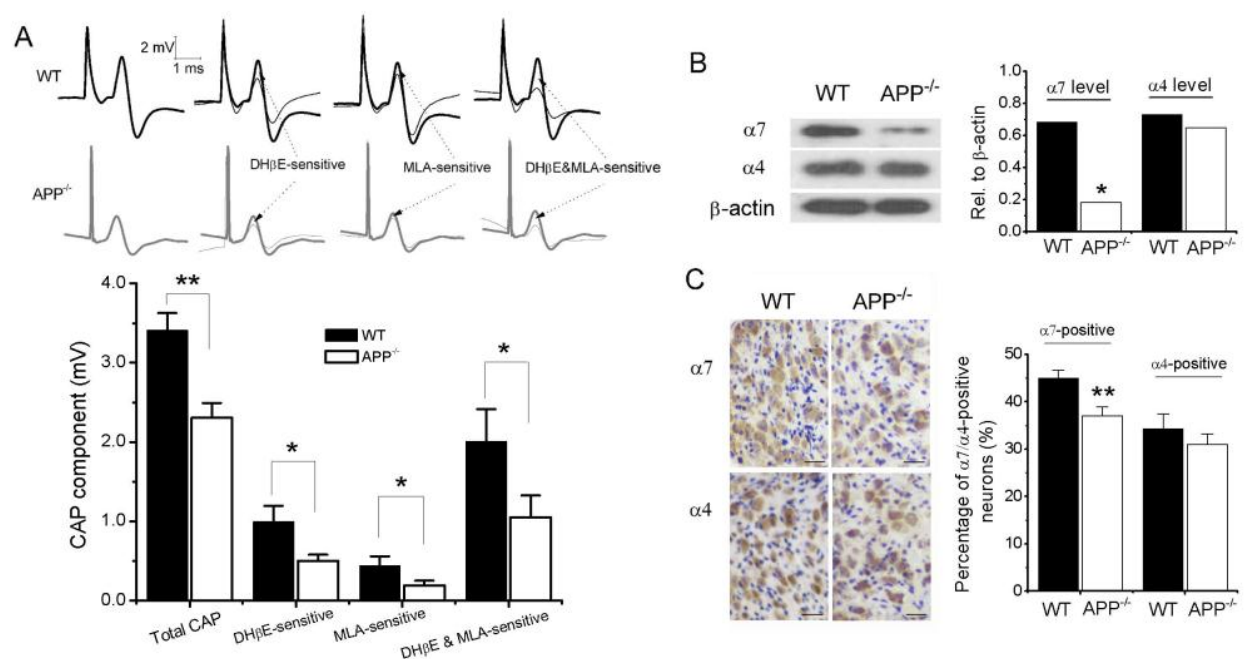



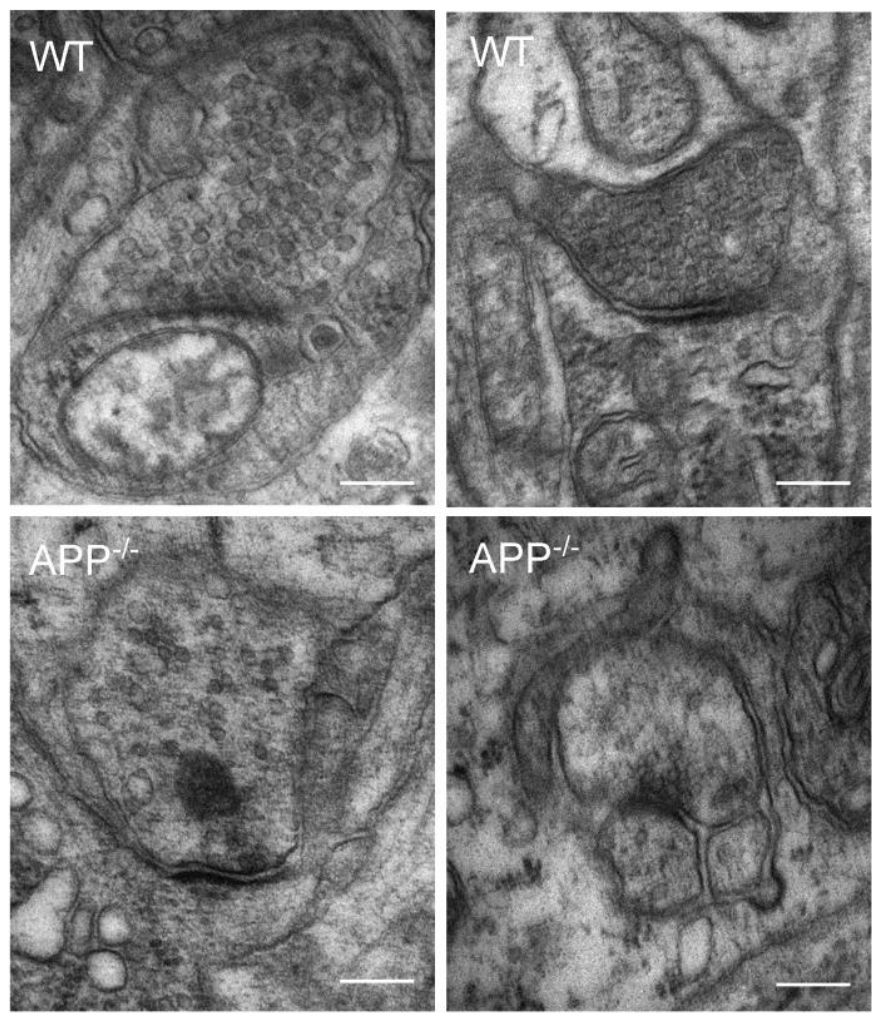


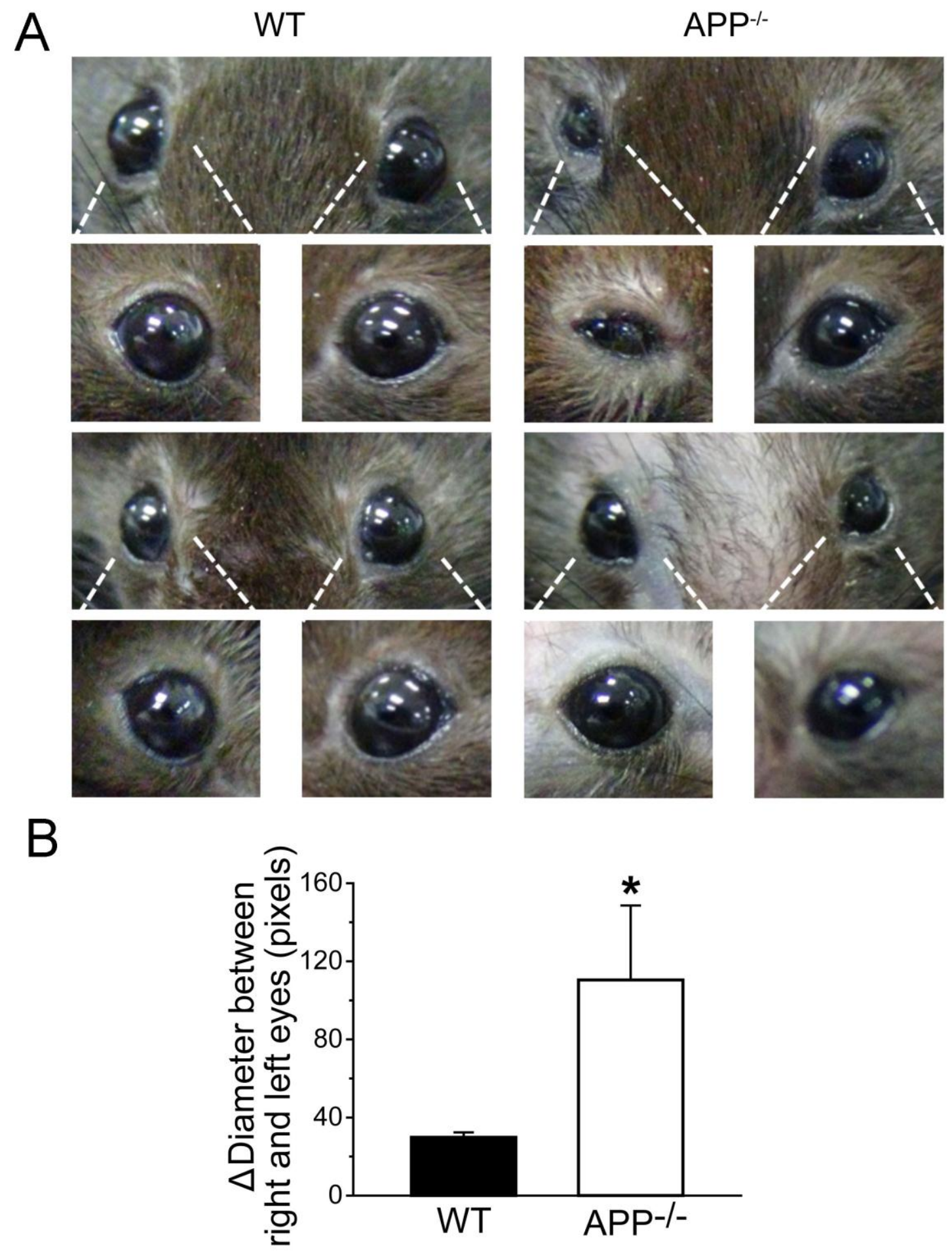

